\title{
Tissue-specific expression of the gene encoding hepatocyte nuclear factor 1 may involve hepatocyte nuclear factor 4
}

\author{
Jian-Min Tian and Ueli Schibler \\ Département de Biologie Moléculaire, Sciences II, Université de Genève, CH-1211 Genève-4, Switzerland
}

\begin{abstract}
Hepatocyte nuclear factor 1 (HNF-1) is a transcriptional regulatory protein possibly involved in the activation of many liver-specifically expressed genes. HNF-1 mRNA is restricted to a small number of tissues, suggesting that the HNF-1 gene itself is regulated at the transcriptional level. We have isolated and characterized the promoter region of this gene and have determined its transcriptional potential in several cell types by cell-free transcription and transient transfection experiments. In in vitro transcription assays, an HNF-1 promoter is active in nuclear extracts from liver and kidney, two tissues that contain HNF-1, but silent in nuclear extracts from spleen and lung, which are devoid of this transcription factor. Likewise, in transfection experiments, HNF-1 promoter-chloramphenicol acetyltransferase (CAT) fusion genes are expressed in Hep G2 cells, which express HNF-1, but not in mouse L cells or Hela cells, which do not express HNF-1. In both cell-free transcription and transient transfection assays, a relatively short promoter segment located between positions -82 and -40 is necessary and sufficient to direct cell type-specific HNF-1 transcription. This region contains a single site for a DNA-binding protein that has been tentatively identified as hepatocyte nuclear factor 4 , a member of the steroid hormone receptor family.
\end{abstract}

[Key Words: HNF-1; HNF-4; transcriptional activation; steroid hormone receptor]

Received July 25, 1991; revised version accepted September 12, 1991.

During the development of complex multicellular organisms, certain genes become activated in a highly cell type-specific manner. At least in part, this selective induction of gene activity is governed by transcriptional regulatory proteins that are themselves tissue-specifically regulated (for review, see Maniatis et al. 1987; Ingham 1988; Falvey and Schibler 1990). One such transcription factor is hepatocyte nuclear factor 1 (HNF-1), a transcriptional activator protein enriched in parenchymal hepatocytes. High-affinity binding sites for this protein have been identified in the control regions of several liver-specifically expressed genes (for review, see Crabtree et al. 1991). These include the ones encoding $\alpha$ - and $\beta$ - fibrinogen (Courtois et al. 1987; 1988), $\alpha$-fetoprotein (Courtois et al. 1988; Jose-Estanyol et al. 1989), albumin (Courtois et al. 1988; Lichtsteiner and Schibler 1989), transthyretin (Costa et al. 1989), $\alpha{ }^{-}{ }_{1}$-antitrypsin (Courtois et al. 1988; Monaci et al. 1988), and pyruvate kinase (Vaulont et al. 1989a,b).

Complementary DNAs for HNF-1 have been isolated by molecular cloning techniques in several laboratories (Frain et al. 1989; Baumhueter et al. 1990; Chouard et al. 1990|. Sequence analysis of recombinant HNF-1 DNAs revealed that HNF-1 is a distantly related member of the POU-homeo box family. This protein binds DNA as a dimer via an atypical helix-turn-helix motif and dimer- izes via a short $\alpha$-helical amino-terminal segment (Chouard et al. 1990; Nicosia et al. 1990). In cotransfection (Nicosia et al. 1990) and cell-free transcription experiments (Frain et al. 1989; Lichtsteiner and Schibler 1989|, HNF-1 efficiently trans-activates the transcription of reporter genes carrying appropriate recognition sequences in their promoters. HNF-1, like the products of its putative target genes, accumulates only in a small number of cell types (see Crabtree et al. 1991 and references therein). Likewise, significant levels of HNF-1 mRNA are only detectable in a restricted number of cell types, such as parenchymal hepatocytes and kidney cells, but not in other tissues such as spleen, lung, and brain (Frain et al. 1989; Baumhueter et al. 1990; Kuo et al. 1990; Xanthopoulos et al. 1991). The question now arises how the expression of the HNF-1 gene itself is tissue-specifically regulated.

In this paper we describe the isolation and functional characterization of a DNA region encompassing the HNF-1 promoter. Both in vivo and in vitro analysis identified a cis-acting element located upstream of the TATA box, which appears to have a crucial role in the cell typespecific transcription of the HNF-1 gene. This element is a high-affinity-binding site for another hepatocyte-enriched transcription factor, hepatocyte nuclear factor 4 (HNF-4) (Sladek et al. 1990). 


\section{Results}

\section{Isolation of the HNF-1 promoter region}

The nucleotide sequence of nearly full-length cDNAs for HNF-1 has recently been reported by several groups /see above). A double-stranded DNA fragment spanning the 5 '-proximal 55-nucleotide cDNA sequence (Frain et al. 1989 ) was used as a probe to screen a genomic rat DNA library by hybridization. Two recombinant phage plaques yielding positive signals were purified, and their DNA was isolated. A restriction cleavage site analysis of this DNA revealed two overlapping recombinant phage inserts that share $\sim 5 \mathrm{~kb}$ of sequences and, together, span a region of $\sim 35 \mathrm{~kb}$. As suggested by Southern blot analysis, both of these recombinant DNAs contain an $\sim 655-$ bp SmaI-SacI fragment that hybridizes to the 55-bp probe used in the screening. This fragment was subcloned into a plasmid vector (pBS + ) and was positively identified as part of the HNF-1 gene by a partial nucleotide sequence analysis. The 186 nucleotides adjacent to the SacI site were identical with the corresponding cDNA region upstream of the SacI site (Frain et al. 1989).
The tentative transcriptional start site was determined by an S1 nuclease experiment with RNAs from liver, kidney, lung, and spleen and a quasi-end-labeled singlestranded DNA probe spanning the putative HNF-1 promoter region. The $\mathrm{S} 1$ nuclease-resistant fragments were size fractionated by denaturing polyacrylamide gel electrophoresis alongside the four dideoxy sequencing reactions obtained by primer extension on the same singlestranded DNA that was used as a template for the production of the DNA probe. As shown in Figure 1A, two bands of $\sim 250$ nucleotides are observed with liver and kidney RNA but not with spleen, lung, and yeast RNA. On the basis of this experiment we tentatively determined the start site on the HNF-1 promoter sequence as indicated in Figure 1B.

Figure 1B displays the nucleotide sequence between position -250 and +100 . As expected, a TATA box-like sequence, GATAAATA, is located between 23 and 30 nucleotides upstream of the transcriptional start site.

Tissue-specific transcription from the HNF-1 promoter The cell-free transcription system developed by Gorski
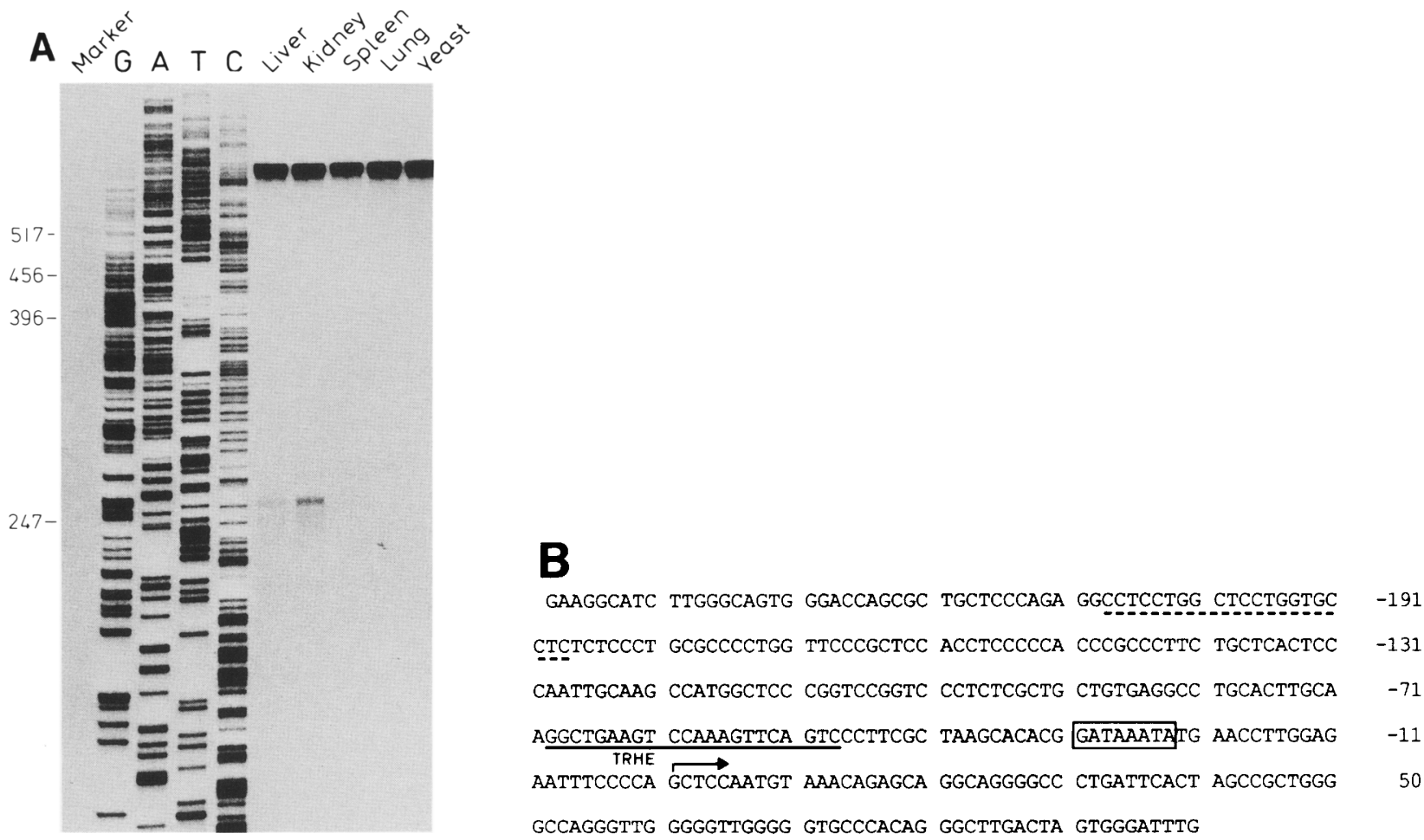

Figure 1. The HNF-1 transcription start site. $(A)$ S1 nuclease mapping of HNF-1 transcripts. S1 nuclease-protected DNA fragments obtained by hybridization of a single-stranded HNF-1 DNA probe $(-401 /+255)$ with $200 \mu \mathrm{g}$ each of RNA from liver, kidney, spleen, lung, and yeast were separated alongside the four sequencing reactions. These were obtained by extension of the primer used in the preparation of the S1 nuclease DNA probe in the presence of dideoxynucleotides and $\left[\alpha^{-32} \mathrm{P}\right] \mathrm{dATP}$. The strong signal migrating more slowly than the 517-nucleotide marker probably represents some self-protection of the DNA probe by contaminating plus strand. $(B)$ Nucleotide sequence around the transcriptional start site of the HNF-1 promoter. Both strands were sequenced according to the dideoxy chain-termination procedure of Sanger et al. (1977). The putative position of the transcriptional start site, as deduced from the S1 nuclease mapping described above, is indicated by an arrow. An A-rich TATA box-like sequence, located upstream of the transcription initiation site, is framed. The underlined nucleotide region was strongly protected from DNase I digestion in the presence of liver nuclear proteins. The DNA segment underlined with a dotted line corresponds to a partial DNase I footprint observed only with high concentrations of nuclear proteins (see Fig. 5). 
et al. (1986) has proven valuable in the rapid identification of important cis-acting promoter elements and trans-acting factors possibly involved in the tissue-specific expression of the serum albumin gene (Maire et al. 1988; Lichtsteiner and Schibler 1989; Descombes et al. 1990; Mueller et al. 1990; Wuarin et al. 1990). Therefore, we decided to examine whether cell type-specific HNF-1 transcription can also be mimicked in vitro. In pilot experiments we adapted the cell-free transcription assays to additional tissues, such as kidney and lung, which had not been used previously in such studies. As a result of their high content in proteases, these tissues have been a poor source for transcriptionally active nuclear extracts. However, by performing the initial tissue homogenization in a cocktail containing $1 \%$ low-fat milk (Maire et al. 1989), this problem could be overcome, such that nuclear extracts with a similar transcriptional potential can now be routinely obtained from liver, spleen, lung, and kidney (see below). These four tissues were chosen because they include two expressing and two nonexpressing tissues with regard to HNF-1 mRNA.

To construct a reporter gene for cell-free transcription assays, an HNF-1 promoter region spanning $\sim 400$ nucleotides $(-401$ to +1$)$ was inserted into a plasmid vector upstream of a 380-bp G-free cassette (Sawadogo and Roeder 1985). This template, together with the plasmid $\operatorname{AdML}(190)$, carrying the adenovirus major late promoter fused to a 190-bp G-free cassette (Lichtsteiner and Schibler 1989; Maire et al. 1989), was incubated in nuclear extracts from liver, kidney, spleen, and lung. As shown in Figure 2, the HNF-1 promoter is utilized efficiently in liver and kidney nuclear extracts but is silent in lung and spleen extracts. As strong transcription signals are observed for the adenovirus major late promoter with nuclear extracts from all four tissue sources, the differential in vitro transcription from the HNF-1 promoter is not attributable merely to a different quality of

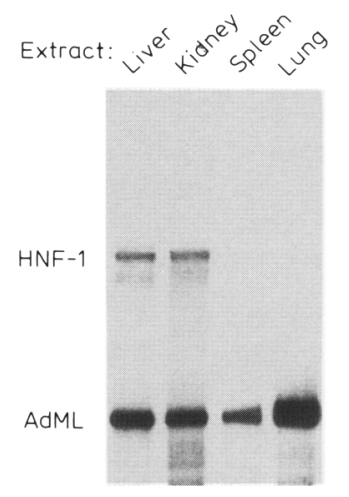

Figure 2. Tissue-specific in vitro transcription from the HNF-1 promoter. Equimolar mixtures of two G-free cassette plasmids ( $800 \mathrm{ng}$ each), carrying either the HNF-1 promoter (HNF-1) or the adenovinus major late (AdML) promoter, were incubated for in vitro transcription with nuclear extracts prepared from liver, kidney, spleen, and lung. The lengths of HNF-1 and adenovirus major late promoter in vitro transcripts are 380 and 190 nucleotides, respectively.

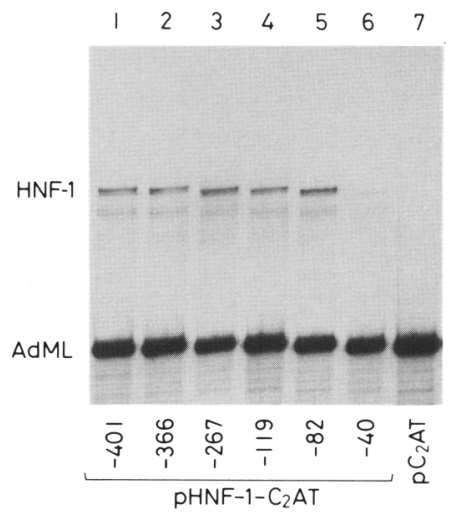

Figure 3. Analysis of deleted HNF-1 promoter versions by cellfree transcription. G-free cassette templates carrying various amounts of HNF-1 5'-flanking sequences were transcribed in vitro in liver nuclear extracts. An adenovirus major late (AdML) promoter containing G-free cassette plasmid was included as an internal standard. The $5^{\prime}$-deletion end points within the HNF-1 promoter are indicated at bottom. $\mathrm{pC}_{2} \mathrm{AT}$ is the parent $\mathrm{G}$-free cassete plasmid that is devoid of a promoter. Quantification of the results: The polyacrylamide regions containing the HNF-1 and adenovirus major late promoter in vitro transcripts were excised and counted. The ratio of HNF-1 to adenovinus major late promoter in vitro transcripts was determined for each HNF-1 promoter-less G-free cassette template and normalized with regard to the value obtained with the longest promoter fragment tested $(-401 \mathrm{bp})$. This value was arbitrarily set at $100 \%$. The average values (in italics below) obtained from two independent experiments (individual values in parentheses) follow: (Lane 1) $100(100,100)$; (lane 2) 103 (92, 114); (lane 3) 151 $(203,98)$; (lane 4) $116(92,139)$; (lane 5) $163(162,163)$; (lane 6) 27 $(32,22)$; (lane 7$)$ (promoter-less G-free cassette vector) $8(11,5)$.

nuclear extracts. Thus, the HNF-1 in vitro transcription pattern closely mimics the HNF-1 expression observed in vivo.

To further define the cis-acting elements responsible for tissue-specific HNF-1 in vitro transcription, promoter sequences were progressively deleted in a $5^{\prime} \rightarrow 3^{\prime}$ direction and the resulting mutant plasmids were assayed for transcriptional activity in a liver nuclear extract. As shown in Figure 3, sequences upstream of position -82 have little, if any, influence on the amplitude of in vitro transcription. However, further deletion of sequences down to position -40 results in a significant decrease in the transcription signal. Therefore, sequences located between -82 and -40 appear to be necessary and sufficient for in vitro transcription from the HNF-1 promoter.

To examine the validity of the in vitro transcription experiments, the efficiencies of progressively deleted HNF-1 promoters were also measured in living cells. To this end, HNF-1-chloramphenicol acetyltransferase (CAT) fusion plasmids were transfected into human HepG2 cells, which express their endogenous HNF-1 gene, or human Hela cells and mouse LTK-cells, which do not express their endogenous HNF-1 gene. Two days after transfection the CAT activity was determined in 
lysates of transfected cells. Figure 4A demonstrates that all fusion gene constructs carrying HNF-1 5 '-flanking sequences $\geqslant 82$ nucleotides give rise to measurable CAT activities in cells of hepatic origin (HepG2). In keeping with the in vitro results described above, a further deletion to -40 strongly attenuates the transcriptional activity of the HNF-1 promoter. No significant CAT activities could be measured in extracts from transfected LTK cells (Fig. 4B) or HeLa cells (Fig. 4C). In contrast, similar CAT activities were obtained for all three cell lines transfected with pSV-CAT (see lane 1 in Fig. 4A,B,C), a plasmid from which CAT mRNA transcription is driven by an SV40 viral promoter, suggesting that the differential expression of the HNF-1-CAT fusion genes cannot be accounted for by a differential transfection efficiency.

In conclusion, the experiments described in this section suggest that a relatively short promoter segment,

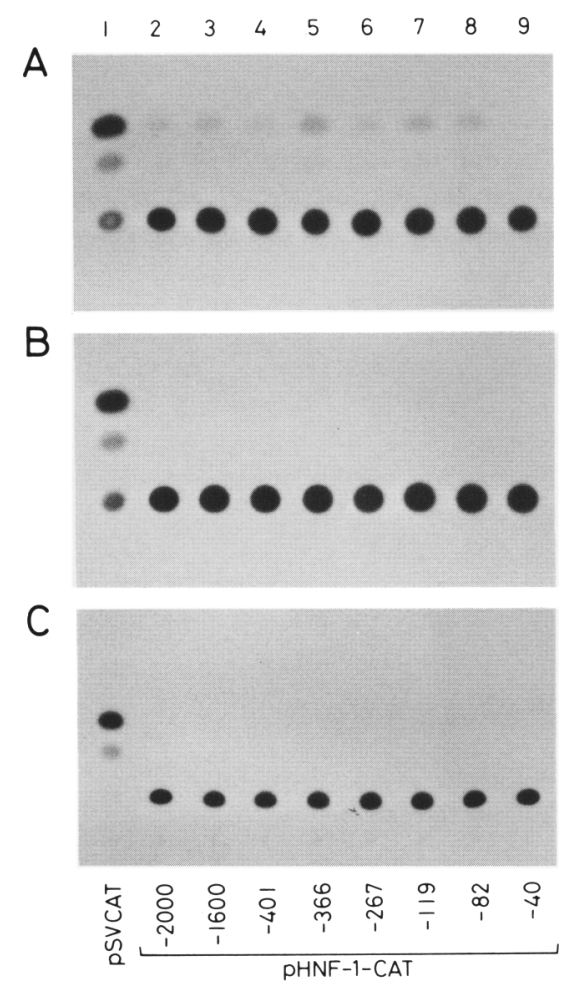

Figure 4. Expression of various HNF-1 promoter-CAT fusion genes in transiently transfected cells. CAT fusion genes carrying various portions of HNF-1 promoter sequences $(5$ '-deletion end points marked below $(C)$ were transfected into either HepG2 hepatoma cells $(A)$, LTK cells $(B)$, or HeLa cells $(C)$. The plasmid pSV-CAT, carrying the SV40 early enhancer-promoter sequences, was included in each transfection series to monitor for relative transfection efficiencies. The CAT activities obtained in HepG2 cells were determined and are expressed as percentages of the activity obtained with the CAT reporter gene carrying the longest HNF-1 promoter fragment $(-2 \mathrm{~kb})$. The average values (in italics below) of two independent experiments (in parentheses) follow. (Lane 2) $100(100,100)$; (lane 3) $149(182,116)$; (lane 4) $313(542,83)$; (lane 5) 275 (290, 260); (lane 6) $159(213,104)$; (lane 7) $246(304,187)$; (lane 8) 195 (243, 146); (lane 9) $21(26,16)$.

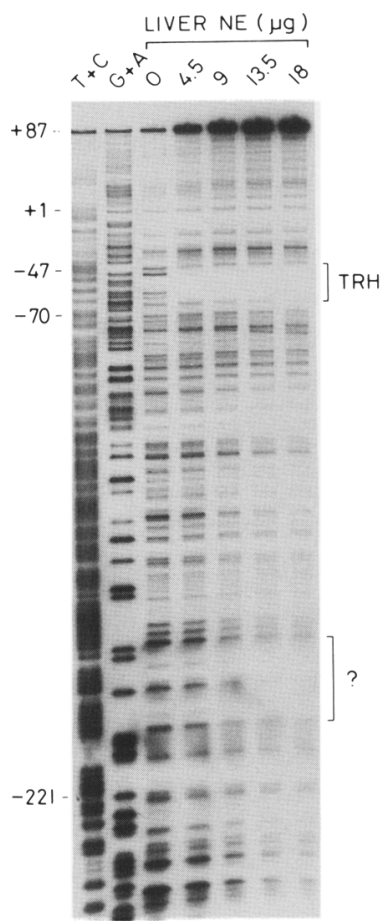

Figure 5. DNase I protection analysis of an HNF-1 promoter fragment with liver nuclear extract. An end-labeled DNA fragment encompassing the transcriptional start site $(+1)$ was incubated in $20-\mu \mathrm{l}$ reactions with liver nuclear proteins (amounts indicated at top of lanes) before partial digestion with DNAse I. The digestion products were size fractionated alongside $T+C$ and $\mathrm{G}+\mathrm{A}$ Maxam-Gilbert degradation products of the same end-labeled fragment by electrophoresis on a $5 \%$ denaturing polyacrylamide gel. The precise boundaries of the TRH footprint were determined in a similar experiment with a fragment end-labeled at position -119 (data not shown). The nature of the protein responsible for the partial footprint centered around -190 is unknown.

located between -82 and -40 , plays an essential role for the cell type-specific transcription of HNF-1, both in cell-free transcription and transient transfection experiments.

\section{A single promoter element is required for cell type-specific in vitro transcription}

Promoter and/or enhancer elements usually stimulate transcription by binding sequence-specific positively acting transcription factors. To screen the HNF-1 promoter region for the presence of binding sites for putative trans-activator proteins, DNase I protection studies were performed with transcriptionally active liver nuclear extracts. As shown in Figure 5, at moderate protein concentrations (up to $9 \mu \mathrm{g} / 20 \mu \mathrm{l}$ ) a single DNase I-resistant region $(-48$ to -69$)$ can be discerned within an end-labeled HNF-1 promoter fragment. This region, the boundaries of which are shown in Figure 1B, was named TRH (for transcriptional regulatory element of HNF-1). At higher inputs of liver nuclear extracts, an additional 
weak footprint centered around -190 is observed. Because we could not attribute a clear functional significance to this promoter segment $(-267$ to -119 , see Fig. 3 and 4) on the basis of our cell-free transcription and transfection studies, we did not undertake any further attempts to characterize this weak binding site in greater detail.

To examine the possible involvement of TRH in the enhancement of transcription from the HNF-1 promoter, a double-stranded oligonucleotide encompassing this DNA element was synthesized and used as a competitor in cell-free transcription assays with liver nuclear extracts (Fig. 6). The addition of synthetic TRH oligonucleotide reduces in vitro transcription from an HNF-1 promoter containing this binding site $(-82$; Fig. 6 , lanes $1-3$ ) to the basal level observed with an HNF-1 promoter lacking TRH $(-40$; Fig. 6, lanes 4-6). Inhibition is specific, as the same concentration of another doublestranded oligonucleotide, the albumin promoter element $B$, does not affect in vitro transcription from the HNF-1 promoter (Fig. 6, lanes 7-12). Incidentally, this control oligonucleotide is a high-affinity binding site for HNF-1 itself. The failure of this DNA fragment to interfere with

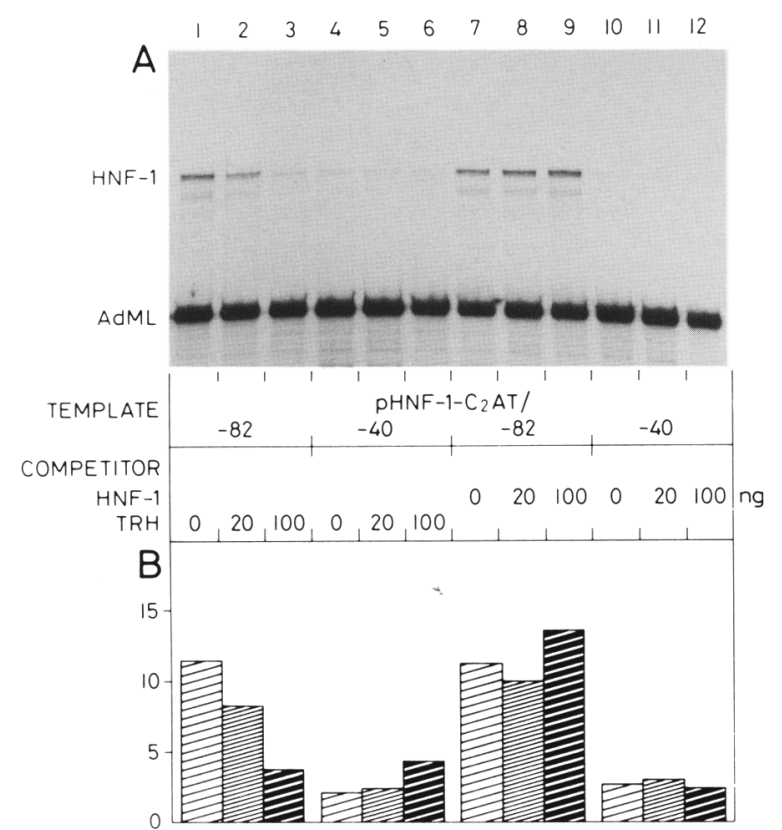

Figure 6. In vitro transcription from the HNF-1 promoter in the presence of competitor oligonucleotides. $(A) \mathrm{G}$-free cassette plasmids bearing either 82 or 40 nucleotides of HNF-1 5'-flanking sequences were transcribed in liver nuclear extracts either in the presence (20 or $100 \mathrm{ng}$ ) or absence $(0 \mathrm{ng}$ ) of two different double-stranded competitor oligonucleotides. One oligonucleotide, TRH, spans the DNase I footprint between positions -47 and -70 of the HNF-1 promoter (see Fig. 5). The other oligonucleotide, HNF-1, contains the strong HNF-1-binding site of the mouse albumin promoter (albumin promoter element $B$; see Lichtsteiner et al. 1987). (B) Quantification of the data shown in $A$. The amounts of HNF-1 in vitro transcripts are expressed as percentages of the in vitro adenovirus major late promoter transcripts, produced in the same reactions.

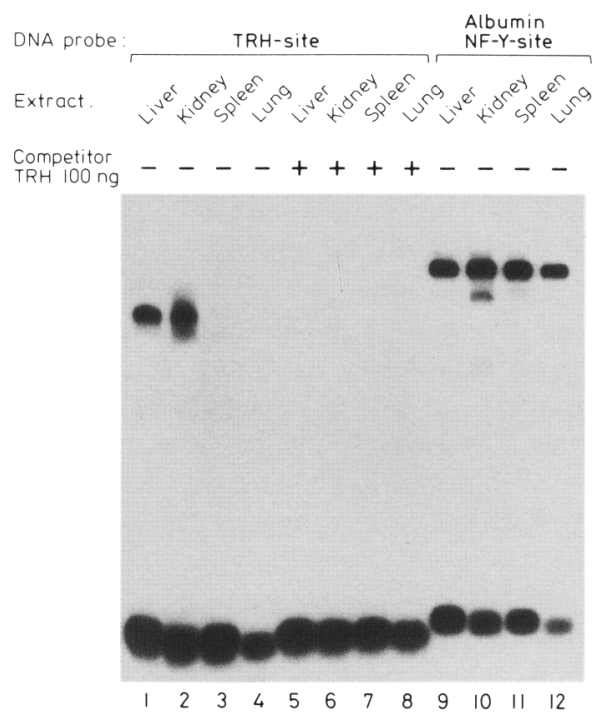

Figure 7. Tissue distribution of the transcription factor binding to the HNF-1 promoter element TRH. Mobility-shift assays were performed with nuclear extracts from liver, kidney, spleen, and lung ( $\sim 5 \mu \mathrm{g}$ each) and a synthetic double-stranded oligonucleotide spanning the HNF-1 promoter element TRH in the absence (lanes 1-4) or presence (lanes 5-8) of unlabeled TRH competitor oligonucleotide. An albumin promoter element binding the ubiquitous CCAAT factor NF-Y was used in the gel mobility-shift assays shown in lanes 9-12 to compare the qualities of the four nuclear extracts.

HNF-1 transcription suggests that, at least in our simple assay system, HNF-1 does not activate its own transcription via an autoregulatory circuit. More likely, another transcriptional activator, the tentative identification of which will be described below, appears to control HNF-1 transcription in vitro and, by inference from the sequence requirement, in vivo.

TRH is the only cis-acting regulatory element within the HNF-1 promoter for which we were able to demonstrate a clear-cut enhancing effect in cell-free transcription and transient transfection. Therefore, this element should also account for the cell type specificity of HNF-1 transcription. According to the most straightforward prediction, the TRH cognate factor would be expected to accumulate at higher levels in HNF-1-expressing tissues, such as liver and kidney, than in nonexpressing tissues, such as spleen and lung. This simple hypothesis was examined by electrophoretic mobility-shift assays, with the double-stranded TRH oligonucleotide as a labeled DNA probe. As shown in Figure 7, specific protein-DNA complexes with identical mobilities can be discerned with nuclear liver and kidney but not with lung and spleen nuclear extracts (Fig. 7, lanes 1-8). This does not merely reflect an inferior quality of the latter two extracts, as these extracts are similarly competent with regard to in vitro transcription from the adenovirus major late promoter as the former two extracts (Fig. 2A). Moreover, all four extracts contain comparable amounts of undergraded NF-Y, a ubiquitous CCAAT-binding fac- 
tor with affinity to the albumin promoter element C (Fig. 7, lanes 10-12).

\section{Identification of the TRH-binding factor}

Inspection of the TRH sequence reveals striking similarity (10 of 12) with the consensus sequence for HNF-4 proposed by Sladek et al. (1990). Moreover, the tissue distribution of HNF-4 mRNA correlates well with the nuclear factor binding to the TRH element within the HNF-1 promoter, in that it accumulates in liver and kidney but not in spleen and lung (Sladek et al. 1990). In a mobility-shift assay with crude liver nuclear extract, complexes with similar mobilities are formed with double-stranded oligonucleotides APF-1, which encompasses a bona fide HNF-4 recognition sequence [from the apolipoprotein CII (apoCIII) gene promoter], and TRH (Fig. 8A). It appeared feasible, therefore, that TRH would be a recognition sequence for HNF-4. In keeping with this hypothesis, unlabeled TRH or APF-1 oligonucleotides compete similarly well for binding to the radiolabeled TRH and APF-1 DNA probes. In contrast, a well characterized HNF-3-binding site derived from the transthyretin promoter (Lai et al. 1990) does not interfere with the formation of protein-TRH or protein-APF-1 complexes. To examine further the similarity between HNF-4 and the TRH-binding protein, the latter protein was partially purified by heparin-agarose chromatography, followed by DNA-Sepharose affinity chromatography (twice successively) on a resin carrying covalently linked multimerized TRH elements. The protein was then photo-cross-linked to its radio-labeled TRH-binding site and size-fractionated by SDS-PAGE. As shown in Figure $8 \mathrm{~B}$, the cross-linked protein-DNA complex migrates at $56 \mathrm{kD}$, consistent with the apparent molecular mass of $54 \mathrm{kD}$ for HNF-4 as measured by Sladek et al. (1990). When cross-linking is performed in the presence of a large excess of unlabeled TRH oligonucleotide, the labeled protein-DNA complex can no longer be observed.

Finally, we examined whether the TRH-binding protein is immunologically related to HNF-4. To this end, electrophoretic mobility-shift assays were performed in the presence of a polyclonal HNF-4 antiserum (generously provided by F. Sladek and J. Darnell) by using liver nuclear extracts incubated with the TRH oligonucleotide. As shown in Figure 8C, a large proportion of the protein-TRH complex reacts with HNF-4 antibodies, giving rise to two additional complexes with lower mobilities.

In conclusion, the TRH-binding protein and HNF-4 share DNA-binding specificity, size, and immunologically detectable epitopes. Together, these findings strongly suggest that the two proteins are identical.

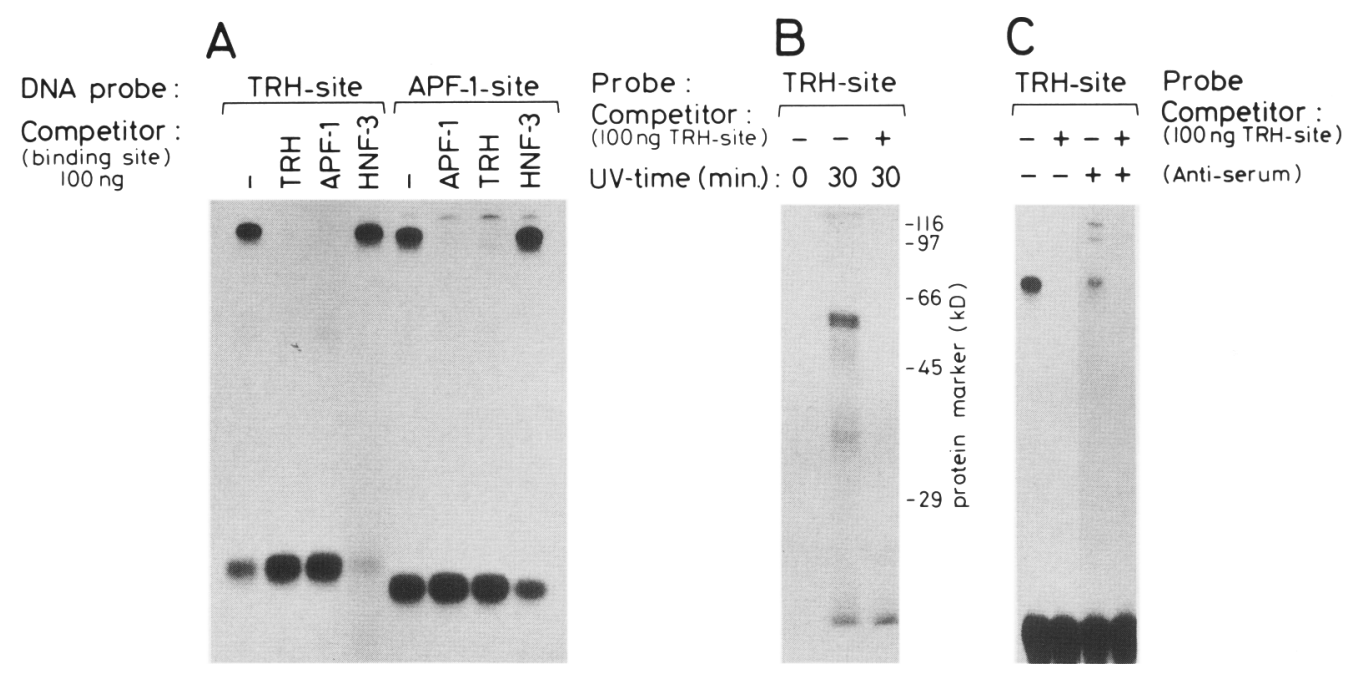

Figure 8. Identification of the TRH-binding protein. $(A \mid$ Electrophoretic mobility-shift assays with oligonucleotides that span different binding sites. The TRH oligonucleotide (HNF-1 promoter) and APF-1 oligonucleotide (bona fide HNF-4 recognition sequence from the apoCIII gene promoter; Sladek et al. 1990) were end labeled and used as probes in electrophoretic mobility-shift assays with liver nuclear extract. The same oligonucleotides and an oligonucleotide containing an HNF-3 recognition sequence from the transthyretin promoter (Lai et al. 1990) were used as competitors (indicated at top). (B) UV cross-linking of affinity-purified TRH-binding protein with its radiolabeled recognition sequence in the absence $(-\mid$ and presence $|+|$ of unlabeled binding site. The predominant radiolabeled protein-DNA complex migrates with an apparent molecular mass of $56 \mathrm{kD}$. (C) Immunological reactivity of the TRH-binding protein with HNF-4 antiserum. Electrophoretic mobility-shift assays with liver nuclear extracts and radiolabeled TRH oligonucleotide were performed in the absence or presence of HNF-4 antiserum. Five microliters of a $1 / 100$ dilution of the antiserum was used in a final reaction volume of $20 \mu 1$. The antiserum was diluted in PBS containing 3\% BSA. As a control for binding specificity, protein-DNA complex formation was inhibited by the addition of unlabeled competitor TRH oligonucleotide. 


\section{Discussion}

HNF-1, a gene specifying a protein thought to be involved in the transcriptional regulation of many liverspecifically expressed genes, is itself expressed in only a subset of cell types (Frain et al. 1989; Kuo et al. 1990; Xanthopoulos et al. 1991|. To elucidate the molecular basis for this tissue-specific expression, genomic clones encompassing the HNF-1 promoter have been isolated and functionally characterized by cell-free transcription and transient transfection experiments. In both assay systems, a relatively short DNA segment located between -82 and -40 can direct cell type-specific transcription from the HNF-1 promoter. In vitro, G-free cassette reporter genes carrying this element yield transcripts in nuclear extracts from liver and kidney but are silent in spleen and lung nuclear extracts. Likewise, transfected HNF-1 promoter-CAT fusion genes containing this element are active in HepG 2 hepatoma cells but inactive in $\mathrm{LTK}^{-}$cells or HeLa cells. In all of these situations there is a perfect correlation between the expression of the endogenous HNF-1 gene, at least with regard to the production of functional mRNA and protein /see below), and the exogenously added reporter genes driven by the HNF-1 promoter. The promoter segment $\{-82$ to -40 ) responsible for this cell-type-specific transcription bears a single binding site (TRH) for a nuclear factor whose tissue distribution correlates with the in vivo and in vitro activity of the HNF-1 promoter. On the basis of its DNA-binding properties, size, and immunologically detectable epitopes, this nuclear factor has been identified as HNF-4.

Surprisingly, in vitro-elongated nascent transcripts hybridizing to HNF-1 cDNA probes have recently been observed in spleen, a tissue that accumulates neither HNF-1 mRNA nor protein (Xanthopoulos et al. 1991). As the $5^{\prime}$ ends of these nascent RNA chains have not yet been mapped it remains to be determined whether they are initiated within the HNF-1 promoter region discussed in this paper.

Recently, an HNF-4 cDNA has been isolated and characterized by Sladek et al. (1990). This transcription factor binds DNA via a zinc finger domain and appears to be a member of the steroid hormone receptor superfamily. HNF-4-binding activity and HNF-4 mRNA accumulation are restricted to a small number of tissues, including liver, kidney, and intestine. In liver, HNF-4 may be required for efficient transcription of the genes encoding transthyretin, apoCIII, and $\alpha_{1}$-antitrypsin (for references, see Sladek et al. 1990). These three putative HNF-4 target genes all produce abundant proteins that fulfill important liver functions in the differentiated organism. As suggested by the experiments described in this paper, HNF-4 may also be a crucial regulatory protein for the expression of a gene specifying another liver-enriched transcriptional activator, HNF-1. Interestingly, HNF-1 and HNF-4 appear to cooperate in the transcriptional activation of several liver-specific genes, including $\alpha_{1}$-antitrypsin (Monaci et al. 1988; Costa et al. 1989; Sladek et al. 1990) and transthyretin (Costa et al. 1989). This ex- emplifies the complex regulatory circuitry involved in the control of tissue-specific gene transcription. A cell type-enriched transcription factor may orchestrate the coordinated accumulation of another cell type-enriched regulatory protein. The two transcription factors may then efficiently activate transcription of downstream genes by a synergistic action.

The transcriptional regulation of several genes encoding tissue-specific transcription factors accumulating in nonhepatic tissues has been studied. These include Pit1-GHF-1, a pituitary gland-specific POU homeo-domain protein (Chen et al. 1990; McCormick et al. 1990), a MyoD-related family of muscle-specific helix-loop-helix proteins (for review, see Olson 1990), and the erythroid factor GATA-1 (Tsai et al. 1991). In all of these cases, the transcription factor can apparently autoregulate its own expression by binding to the promoter of its own gene. The obvious advantage of autoregulation is that it assures the maintenance of factor expression, once induced. Thus far, there is no evidence for a similar autoregulation for HNF-1 expression, as no binding site for HNF-1 could be identified within the proximal promoter region directing cell type-specific expression. Nevertheless, our results cannot exclude that in the intact animal, HNF-1 participates in its own transcriptional control via remote upstream or downstream cisacting elements not yet characterized in this study.

The architecture of the HNF-1 promoter, as revealed by protein-binding studies with unfractionated liver nuclear extract, looks pleasingly simple. The only binding site occupied at low-to-moderate protein input is TRH, a high-affinity HNF-4-binding site. In contrast, the promoters of HNF-1 target genes, such as the ones encoding albumin or $\alpha$-fetoprotein, contain a series of closely spaced binding sites for a bewildering variety of different sequence-specific transcription factors (for review, see Crabtree et al. 1991). Conceptually, this difference in complexity would be expected for promoters directing the production of rare regulatory proteins and abundant proteins. At least in part, the transcription initiation frequency at a given promoter depends on the number of cis-acting elements it contains.

\section{Materials and methods}

Selection of rat genomic clones containing the HNF-1 promoter region

About $10^{6}$ recombinant phage plaques of an amplified EMBL3-rat DNA genomic library (generously provided by P. Maire and A. Kahn, INSERM, Paris| were screened by hybridization with a synthetic DNA fragment encompassing the $5^{\prime}$-proximal 55 nucleotides of nearly full-length HNF-1 cDNA (Frain et al. 1989). This hybridization probe was obtained by annealing the two oligonucleotides 5'-GGTGCCCACAGGGCTTGACTAGTGGGATTTGGGGG-3' and ${ }^{\prime}$ '-TCACCCTAAACCCCCTCGGTCACCCACGTCGCTCGG-5' (complementary regions underlined) and by filling in the $5^{\prime}$ overhangs with Klenow DNA polymerase in the presence of $\left[\alpha^{-32} \mathrm{P}\right]$ dATP $(3000 \mathrm{Ci} / \mathrm{mmole})$. Ten $15-\mathrm{cm}$ petri dishes were seeded with $\sim 10^{5} \mathrm{PFU}$ each of the 
recombinant library and incubated overnight at $37^{\circ} \mathrm{C}$. Duplicate phage lifts were prepared from each dish as described in Sambrook et al. (1989). The filters were prewashed, hybridized with $\sim 5 \times 10^{6} \mathrm{cpm} /$ filter of the denatured DNA probe, and washed according to standard procedures (Sambrook et al. 1989). Four double-positive phage plaques were purified, and their DNA was characterized by restriction digestion with the endonucleases EcoRI, BamHI, HindIII, SacI, PstI, SphI, SalI, and combinations of these enzymes. This analysis revealed two independent and overlapping HNF-1 clones (three of the four being identical) containing $\sim 20=\mathrm{kb}$ inserts each. Together, these two recombinant DNAs encompass $\sim 35 \mathrm{~kb}$ of the HNF-1 locus.

\section{Construction of HNF-1 promoter fusion genes for in vitro transcription and transfection studies}

The G-free cassette vector $\mathrm{p}\left(\mathrm{C}_{2} \mathrm{AT}\right) 19$ (Sawadogo and Roeder 1985 and the pCAT-0 vector were used for construction of HNF-1 promoter fusion genes in cell-free transcription experiments and transfection studies, respectively.

An EcoRI-SacI fragment containing $-2 \mathrm{~kb}$ of $5^{\prime}$-flanking sequences, in addition to 186 nucleotides of 5 ' mRNA sequences, was subcloned into the plasmid vector $\mathrm{pBS}+$. The resulting recombinant plasmid was cleaved with SpeI $(+92)$, blunted by Klenow polymerase, and cleaved with $\mathrm{XbaI}$. The resulting HNF-1 fragment $(-2000 /+92)$ was cloned between the SmaI and $\mathrm{XbaI}$ sites of the CAT vector pEMBL $19+/ \mathrm{CAT} /$ upstream mouse sequence (UMS) (Heard et al. 1987) (generously provided by P. Maire, Paris). This plasmid served as a source for all deletion mutants, which were constructed as follows: The above donor plasmid was cleaved with different restriction enzymes removing increasing portions of the 5 - flanking sequences of the HNF-1 promoter. After blunting the ends with T4 DNA polymerase (if necessary) the promoter-containing fragment was cleaved with SacI, which cuts in the polylinker of the pEMBL19+/CAT/UMS vector just downstream of +92 . The resulting fragments of different lengths were inserted between the SmaI-SacI sites of the pEMBL19+/CAT/UMS vector. The following enzymes were used for the 5 -terminal truncations: PstI $(-1.6 \mathrm{~kb})$, SmaI $(-401)$, FokI $(-366)$, DraI (267), NcoI $(-119)$, StuI $(-82)$, and DdeI $(-40)$.

For the construction of in vitro transcription templates, the G-free cassette was excised from the parent plasmid with SacISmaI, blunt-ended with T4 DNA polymerase, and inserted into various portions of HNF-1 $5^{\prime}$-flanking sequences that contain pBS + . In all cases, the $3^{\prime}$ end (with regard to the upper strand) of these fragments was defined by an AluI site. The following enzymes were utilized to create $5^{\prime}$ deletions: $\operatorname{SmaI}(-401)$, FokI $(-366)$, DraI $(-267), N c o I(-119)$, StuI $(-82)$, and DdeI (-40).

\section{S1 nuclease mapping}

A single-stranded, quasi-end-labeled DNA probe for $\$ 1$ nuclease mapping experiments was prepared as follows. Single-stranded plasmid DNA (containing the upper strand of the insert) was obtained by superinfection of an Escherichia coli JM 109 strain harboring a pBS + plasmid carrying the SmaI-SacI HNF-1 promoter fragment $(-401 /+255)$ with the helper phage M13KO7 according to the method described in Sambrook et al. (1989). This single-stranded DNA was annealed with the oligonucleotide 3'-TCAACTCGGTCGACGTCTGCCTCGAG-5' and extended with T7 DNA polymerase (Sequenase; U.S. Biochemical) in the presence of $\left[\alpha^{-32} \mathrm{P}\right] \mathrm{dATP}$, unlabeled dTTP, dGTP, dCTP, and the restriction endonuclease $B a m H I$ according to Descombes et al. (1990). The 660-bp extension product was isolated by gel electrophoresis on a $5 \%$ urea-polyacrylamide gel and used as a single-stranded probe in an S1 nuclease mapping experiment. S1 nuclease mapping was performed as described by Sierra et al. (1990) with $200 \mu \mathrm{m}$ each of whole-cell RNA from kidney, liver, spleen, and lung. RNA was extracted by the guanidium thiocyanate procedure described by Clemens (1984).

DNase I protection and electrophoretic mobility-shift experiments

An end-labeled HNF-1 promoter fragment for DNase I protection experiments was prepared as follows: A recombinant plasmid containing a DraI-SpeI fragment $(-267 /+92)$ inserted into the SmaI site of the pBS + plasmid vector was cleaved at the $X b a \mathrm{I}$ site of the pBS + polylinker upstream of position -267 , treated with calf intestine alkaline phosphatase $|C I P|$, and phosphorylated with polynucleotide kinase in the presence of $\left[\gamma^{-32} \mathrm{P}\right] \mathrm{ATP}$. After digestion with SacI (within the $\mathrm{pBS}+$ polylinker downstream of position +92 ), the resulting end-labeled HNF-1 promoter fragment was purified by low-melting agarose gel electrophoresis. This gel-purified DNA fragment was used as a probe in DNase I protection experiments as described by Lichtsteiner et al. (1987), except for the protein-DNA binding period, which was reduced from 90 to $10 \mathrm{~min}$.

Labeled double-stranded oligonucleotides were prepared as DNA probes for the mobility-shift experiments by annealing two synthetic oligonucleotides and by filling in the $5^{\prime}$ overhangs with Klenow polymerase in the presence of $\left[\alpha^{-32} \mathrm{P}\right] \mathrm{dATP}$. The following oligonucleotides were used:

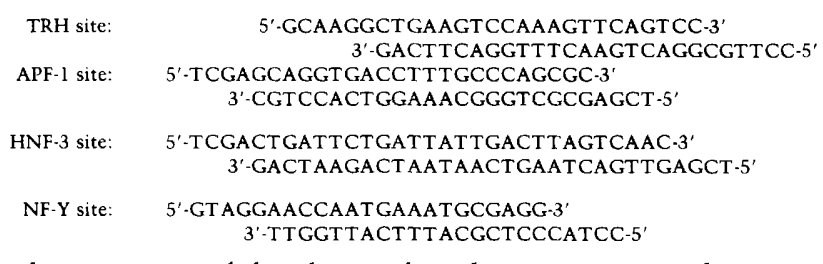

The sequences of the oligonucleotide encompassing the APF-1 element of the apoCIII promoter (Sladek et al. 1990), the HNF3-binding site of the transthyretin promoter (Lai et al. 1990), and the NF-Y-binding site of the albumin promoter (Lichtsteiner et al. 1987) have been described previously. Mobility-shift assays were performed according to Lichtsteiner et al. (1987), except that sonicated double-stranded salmon sperm DNA, rather than poly- $[\mathrm{d}(\mathrm{I}-\mathrm{C})]$ was used as a nonspecific competitor DNA.

\section{Preparation of transcriptionally competent nuclear extracts}

Nuclei from all tissues were purified by a single centrifugation step through concentrated sucrose as described previously (Lichtsteiner and Schibler 1989; Maire et al. 1989). The homogenization buffer included $1 \%$ low-fat milk as a competitive inhibitor for proteolytic enzymes. This is particularly important for protease-rich tissues such as lung and kidney. In vitro transcription assays were conducted essentially as described by Gorski et al. (1986), except that the concentration of the chain terminator 3'-O-methyl-GTP was raised to $0.5 \mathrm{~mm}$.

For the quantification of transcription signals, the regions of the dried polyacrylamide gel containing the radioactive in vitro transcripts were excised and counted in Aquasol (Amersham) in a liquid scintillation counter.

\section{Protein purification}

All manipulations were performed at $0-4^{\circ} \mathrm{C}$. A total of 44 livers from adult male rats (Lewis) were homogenized in 2.2 liters of $2.4 \mathrm{M}$ sucrose homogenization buffer according to Lichtsteiner and Schibler (1989). Nuclei were isolated from $400-\mathrm{ml}$ portions of this homogenate as described previously (Lichtsteiner and Schibler 1989/ and resuspended in a total of $55 \mathrm{ml}$ of nuclear 
lysis buffer [10 mM HEPES (pH 7.6), $100 \mathrm{~mm} \mathrm{KCl,} 3 \mathrm{mM} \mathrm{MgCl}_{2}$, $0.1 \mathrm{~mm}$ DTT, $10 \%$ glycerol, $0.1 \mathrm{~mm}$ PMSF, $0.1 \%$ Trasylol] by homogenization in an all-glass Dounce homogenizer. $\mathrm{NaCl}$ was added to a final concentration of $0.3 \mathrm{M}$. After gentle rocking for $30 \mathrm{~min}$ on ice, the nuclear lysates were centrifuged at 35,000 / $\mathrm{rpm}$ for $\mathrm{l} \mathrm{hr}$ in a Ti60 rotor of a Beckman ultracentrifuge. The supernatant was dialyzed twice for $2 \mathrm{hr}$ against 200 volumes of nuclear lysis buffer. Insoluble material was removed by lowspeed centrifugation, and the supernatant was kept at $-70^{\circ} \mathrm{C}$. Soluble nuclear protein $(650 \mathrm{mg}$ ) was recovered from 44 rats. The crude nuclear extract was loaded on a $30-\mathrm{ml}$ heparin-agarose column, and the proteins were step-eluted with HEM buffer [10 mM HEPES (pH 7.6), $3 \mathrm{~mm} \mathrm{MgCl}_{2}, 0.1 \mathrm{mM}$ EDTA, 1 mM DTT, 10\% glycerol, $0.1 \%$ Trasylol, $0.1 \mathrm{mM}$ PMSF] containing increasing amounts of $\mathrm{KCl}(0.1 \mathrm{M}$ steps from $0.1 \mathrm{M}$ to $0.6 \mathrm{M})$. The fractions were monitored for TRH-binding activity by mobility-shift assays. The $0.4 \mathrm{M}$ and $0.5 \mathrm{M} \mathrm{KCl}$ fractions containing most of the binding activity were combined, dialyzed against HEM buffer containing $0.1 \mathrm{M} \mathrm{KCl}$, and centrifuged at 10,000 rpm in a Sorvall HB-4 rotor to remove insoluble material. The supernatant was complemented with poly $\mathrm{dI}: \mathrm{dC}(1 \mu \mathrm{g} / \mathrm{ml})$, sonicated salmon sperm DNA $(6 \mu \mathrm{g} / \mathrm{ml})$, and NP-40 $(0.1 \%)$. After an incubation for $20 \mathrm{~min}$ on ice, the partially purified extract was applied to a 3-ml DNA-Sepharose column (Kadonaga and Tjian 1986), prepared with multimerized TRH oligonucleotides as described by Lichtsteiner and Schibler (1989). The proteins were step-eluted with HEM buffer containing $0.1 \mathrm{M}$ increments of $\mathrm{KCl}$ and $0.1 \% \mathrm{NP}-40$. The fractions containing most of the TRH-binding activity $(0.3-0.5 \mathrm{M} \mathrm{KCl})$ were pooled and dialyzed against HEM buffer containing $0.1 \%$ of the detergent LDAO and $0.1 \mathrm{M} \mathrm{KCl}$. After addition of sonicated salmon sperm DNA to 1.5 $\mu \mathrm{g} / \mathrm{ml}$, the proteins were repurified on a $1-\mathrm{ml}$ DNA-Sepharose column as described above, except that NP-40 was replaced by the detergent LDAO. This partially purified preparation still contained several protein species as revealed by silver-staining of electrophoretically separated proteins (Laemmli 1970), one of which migrated with an apparent molecular mass of $54 \mathrm{kD}$, expected for HNF-4.

\section{UV photo-cross-linking of protein DNA complexes}

A TRH probe for photo-cross-linking was prepared as follows. The two oligonucleotides

\section{5'-GCAAGGCTGAAGTCCAAAGTT CAGTC C-3'} 3'- CAAGTCAGG-5'

were annealed, and the resulting $5^{\prime}$ overhang was filled in with Klenow polymerase. A $20-\mu$ l reaction contained $300 \mathrm{ng}$ of the annealed oligonucleotide $(225 \mathrm{ng}$ of the $27-\mathrm{mer}$ and $75 \mathrm{ng}$ of the 9-mer), $10 \mathrm{~mm}$ Tris- $\mathrm{HCl}$ ( $\mathrm{pH} 7.5$ ), $10 \mathrm{~mm} \mathrm{MgCl}_{2}, 50 \mathrm{~mm} \mathrm{NaCl}, 1$ mM DDT, $0.25 \mathrm{~mm}$ each of dCTP, dGTP, BrdUTP, $50 \mu \mathrm{Ci}$ of $\left[\alpha^{-}{ }^{32} \mathrm{P}\right] \mathrm{dATP}(400 \mathrm{Ci} / \mathrm{mmole})$, and 5 units of Klenow polymerase. Incubation was for $90 \mathrm{~min}$ at $16^{\circ} \mathrm{C}$. After the addition of dATP to $0.25 \mathrm{mM}$, the reaction was allowed to continue for another 45 $\mathrm{min}$. The labeled probe was separated from unincorporated nucleotides by gel filtration on Sephadex G-50. A total of $1.5 \mathrm{ng}$ of this probe was incubated with $1 \mu \mathrm{l}$ of partially purified TRHbinding protein (HNF-4) in $20 \mu$ l containing $25 \mathrm{~mm} \mathrm{HEPES} \mathrm{(pH}$ 7.6), $10 \mathrm{mM} \mathrm{MgCl}_{2}, 0.5 \mu \mathrm{g}$ poly[d(I-C)], $0.5 \mathrm{~mm} \mathrm{DTT}, 1 \% \mathrm{Tra}-$ sylol, $0.7 \mu \mathrm{g} / \mathrm{ml}$ of pepstatin A, $0.7 \mu \mathrm{g} / \mathrm{ml}$ of leupeptin, $0.1 \mathrm{~mm}$ benzamidine, and $100 \mathrm{ng}$ of sonicated salmom sperm DNA or unlabeled and unsubstituted TRH competitor oligonucleotides. After incubation on ice for $15 \mathrm{~min}$, the tubes were opened, covered with Saran Wrap (to avoid evaporation), and exposed to an inverted Brouwer UV transilluminator $(310 \mathrm{~nm})$ for $30 \mathrm{~min}$ at room temperature at a distance of $4 \mathrm{~cm}$. SDS-loading buffer was then added to the samples, and protein-DNA complexes were resolved by SDS-PAGE (Laemmli 1970).

\section{Other methods}

Conventional recombinant DNA procedures and DNA sequencing (Sanger et al. 1977; Maxam and Gilbert 1980) were carried out as described by Sambrook et al. (1989). Calciumphosphate-mediated DNA transfections and CAT assays with extracts from transfected cells were carried out as described by Mueller et al. (1990).

\section{Acknowledgments}

We thank Francis Sladek and Jim Darnell for their generous gift of HNF-4 antiserum. We thank our colleagues Eileen Falvey, Dan Lavery, and Ed Schmidt for critical reading of the manuscript, Otto Jenny and Fabienne Bujard-Ebener for preparing the illustrations, and Danièle Rifat for synthesizing the oligonucleotides. This work was supported by the Swiss National Science Foundation and the State of Geneva.

The publication costs of this article were defrayed in part by payment of page charges. This article must therefore be hereby marked "advertisement" in accordance with 18 USC section 1734 solely to indicate this fact.

\section{References}

Baumhueter, S., D.B. Mendel, P.B. Conley, C.J. Kuo, C. Turk, M.K. Graves, C.A. Edwards, G. Courtois, and G.R. Crabtree. 1990. HNF-1 shares three sequence motifs with the POU domain proteins and is identical to LF-BI and APF. Genes \& Dev. 4: 372-379.

Chen, R., H.A. Ingraham, M.N. Treacy, V.R. Albert, L. Wilson, and M.G. Rosenfeld. 1990. Autoregulation of pit 1 gene expression mediated by two cis-acting promoter elements. $\mathrm{Na}$ ture 346: 583-586.

Chouard, T., M. Blumenfeld, I. Bach, J. Vandekerckhove, S. Cereghini, and M. Yaniv. 1990. A distal dimerization domain is essential for DNA-binding by the atypical HNF1 homeodomain. Nucleic Acids Res. 18: 5853-5863.

Clemens, M.J. 1984. Purification of eukaryotic messenger RNA. In Transcription and translation: A practical approach (ed. B.D. Hames and S.J. Higgins), pp. 211-230. IRL Press, Oxford.

Costa, R.H., D.R. Grayson, and J.E. Darnell, Jr. 1989. Multiple hepatocyte-enriched nuclear factors function in the regulation of transthyretin and $\alpha 1$-antitrypsin genes. Mol. Cell. Biol. 9: 1415-1425.

Courtois, G., S. Baumhueter, and G.R. Crabtree. 1988. Purified hepatocyte nuclear factor 1 interacts with a family of hepatocyte-specific promoters. Proc. Natl. Acad. Sci. 85: 79377941.

Crabtree, G.R., U. Schibler, and M.P. Scott. 1991. Transcriptional regulatory mechanisms in liver and midgut morphogenesis of vertebrates and invertebrates. In Transcriptional regulation (eds. K.R. Yamamoto and S.L. McKnight) (In press.)

Descombes, P., M. Chojkier, S. Lichtsteiner, E. Falvey, and U. Schibler. 1990. LAP, a novel member of the C/EBP family, encodes a liver-enriched transcriptional activator protein. Genes \& Dev. 4: 1541-1551.

Falvey E. and U. Schibler. 1990. How are the regulators regu- 
lated? FASEB J. 5: 309-314.

Frain, M., G. Swart, P. Monaci, A. Nicosia, S. Stämpfli, R. Frank, and R. Cortese. 1989. The liver-specific transcription factor LF-B1 contains a highly diverged homeobox DNA binding domain. Cell 59: 145-157.

Gorski, K., M. Carneiro, and U. Schibler. 1986. Tissue-specific in vitro transcription from the mouse albumin promoter. Cell 47: 767-776.

Heard, J.M., P. Herbomel, M.-O. Ott, A. Mottura-Rollier, M. Weiss, and M. Yaniv. 1987. Determinants of rat albumin promoter tissue-specificity analyzed by an improved transient expression system. Mol. Cell. Biol. 7: 2425-2434.

Ingham, P.W. 1988. The molecular genetics of embryonic pattern formation in Drosophila. Nature 335: 25-34.

Jose-Estanyol, M., A. Poliard, D. Foiret, and J.-L. Danan. 1989. A common liver-specific factor binds to the rat albumin and alpha-fetoprotein promoters in vitro and acts as a positive trans-acting factor in vivo. Eur. J. Biochem. 181: 761-766.

Kadanoga, J.T. and R. Tjian. 1986. Affinity purification of sequence specific DNA binding proteins. Proc. Natl. Acad. Sci. 83:5889-5893.

Kuo, C.J., P.B. Conley, C. Hsie, U. Franke, and G.R. Crabtree. 1990. Molecular cloning, functional expression, and chromosomal localization of mouse HNF-1. Proc. Natl. Acad. Sci. 87: 9838-9842.

Laemmli, U.K. 1970. Cleavage of structural proteins during the assembly of the head of bacteriophage T4. Nature 227: 680685.

Lai, E., V.R. Prezioso, E. Smith, O. Litvin, R.H. Costa, and J.E. Darnell, Jr. 1990. HNF-3A, a hepatocyte-enriched transcription factor of novel structure is regulated transcriptionally. Genes \& Dev. 4: 1427-1436.

Lichtsteiner, S. and U. Schibler. 1989. A glycosylated liver-specific transcription factor stimulates transcription of the albumin gene. Cell 57: 1179-1187.

Lichtsteiner, S., J. Wuarin, and U. Schibler. 1987. The interplay of DNA-binding proteins on the promoter of the mouse albumin gene. Cell 51: 963-973.

Maire, P., J. Wuarin, and U. Schibler. 1989. The role of cis-acting elements in tissue-specific albumin gene transcription. Science 244: 343-346.

Maniatis, T., S. Goodbourn, and J.A. Fischer. 1987. Regulation of inducible and tissue-specific gene expression. Science 236: 1237-1245.

Maxam, A.M. and W. Gilbert. 1980. Sequencing end-labeled DNA with base-specific chemical cleavages. Methods Enzymol. 65: 499-670.

McCormick, A., H. Brady, L.E. Theill, and M. Karin. 1990. Regulation of the pituitary specific homeobox protein GHFl by cell-autonomous and environmental cues. Nature 345: 829832.

Monaci, P., A. Nicosia, and R. Cortese. 1988. Two liver-specific factors stimulate in vitro transcription from the human $\alpha 1$ antitrypsin promoter. EMBO 1. 7: 2075-2087.

Mueller, C.R., P. Maire, and U. Schibler. 1990. DBP, a liverenriched transcriptional activator is expressed late in ontogeny and its tissue-specificity is determined posttranscriptionally. Cell 61: 279-291.

Nicosia, A., P. Monaci, L. Tomei, R. DeFrancesco, M. Nuzzo, H. Stunnenberg, and R. Cortese. 1990. A myosin-like dimerization helix and an extra-large homeodomain are essential elements of the tripartite DNA binding structure of LF-B1. Cell 61: 1225-1236.

Olson, E.N. 1990. MyoD family: A paradigm for development. Genes \& Dev. 4: 1454-1461.

Sambrook, J., E.F. Fritsch, and T. Maniatis. 1989. Molecular cloning: A laboratory manual, 2nd ed. Cold Spring Harbor Press, Cold Spring Harbor, New York.

Sanger, F., S. Nicklen, and A.R. Coulson. 1977. DNA sequencing with chain-terminating inhibitors. Proc. Natl. Acad. Sci. 74: 5463-5467.

Sawadogo, M. and R.G. Roeder. 1985. Factors involved in specific transcription by human RNA polymerase II. Analysis by a rapid and quantitative in vitro assay. Proc. Nat1. Acad. Sci. 82: 4394-4398.

Sierra, F., F. Tamone, C.R. Mueller, and U. Schibler. 1990. Differential in vitro transcription from the promoter of a rat alpha $2 \mu$ globulin gene in liver and spleen nuclear extracts. $J$. Mol. Med. 7: 131-146.

Sladek, F.M., W. Zhong, E. Lai, and J.E. Darnell Jr. 1990. Liverenriched transcription factor HNF-4 is a novel member of the steroid hormone receptor superfamily. Genes \& Dev. 4: 2352-2365.

Tsai, S.-F., E. Strauss, and S.H. Orkin. 1991. Functional analysis and in vivo footprinting implicate the erythroid transcription factor GATA-1 as a positive regulator of its own promoter. Genes \& Dev. 5: 919-931.

Vaulont, S., N. Puzenat, A. Kahn, and M. Raymonjean. 1989a. Analysis by cell-free transcription of the liver-specific pyruvate kinase gene promoter. Mol. Cell. Biol. 9: 4409-4415.

Vaulont, S., N. Puzenat, F. Levrat, M. Cognet, A. Kahn, and M. Raymonjean. 1989b. Proteins binding to the liver-specific pyruvate kinase gene promoter. A unique combination of known factors. I. Mol. Biol. 209: 205-219.

Wuarin, J., C.R. Mueller, and U. Schibler. 1990. A ubiquitous CCAAT-factor is required for efficient in vitro transcription from the mouse albumin promoter. I. Mol. Biol. 214: 865874.

Xanthopoulos, K.G., V.R. Prezioso, W.S. Chen, F.M. Sladek, R. Cortese, and J.E. Darnell. 1991. The different transcription patterns of genes for HNF-1, C/EBP, HNF-3, and HNF-4, protein factors that govern liver-specific transcription. Proc. Natl. Acad. Sci. 88: 3807-3811. 


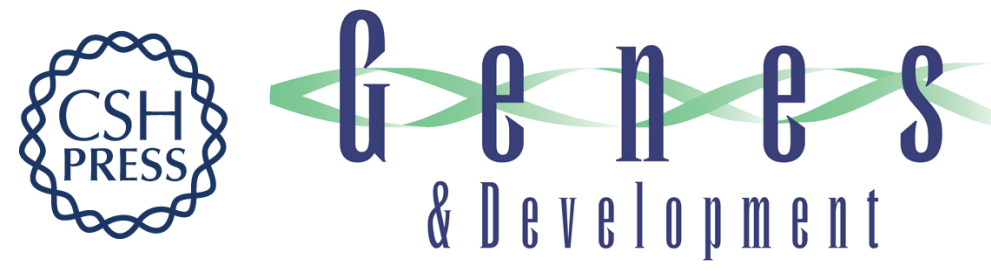

\section{Tissue-specific expression of the gene encoding hepatocyte nuclear factor 1 may involve hepatocyte nuclear factor 4.}

J M Tian and U Schibler

\section{Genes Dev. 1991, 5:}

Access the most recent version at doi:10.1101/gad.5.12a.2225

References This article cites 35 articles, 16 of which can be accessed free at:

http://genesdev.cshlp.org/content/5/12a/2225.full.html\#ref-list-1

License

Email Alerting

Service

Receive free email alerts when new articles cite this article - sign up in the box at the top right corner of the article or click here.

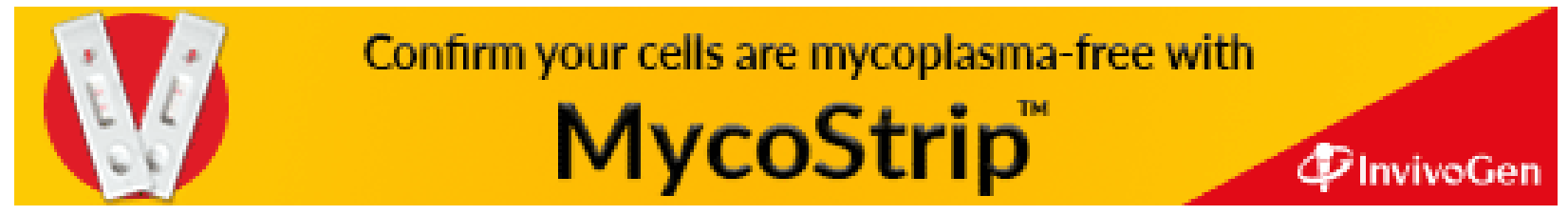

